\title{
Reflexiones sobre
}

la Historia Oral,

la modernidad/

colonialidad y los

procesos sociales

Nuestroamericanos

nicaragüenses.

MSc. Leonardo Danilo González Estrada 


\section{Reflexiones sobre la Historia Oral, la modernidad/ colonialidad y los procesos sociales Nuestroamericanos nicaragüenses.}

MSc. Leonardo Danilo González E. Abogado, Master en métodos de investigación científica. Docente de la Facultad de Ciencias e Ingeniería. UNAN-Managua.

https://orcid.org/0000-0003-3158-737X

leochorotegaunan@gmail.com

Recibido: 09 de marzo 2018

Aceptado: 11 de mayo 2018

(C) () (2) Copyright $\odot 2018$ UNAN-Managua (c) Todos los DerechosReservados.

\section{Reflections on Oral History, Modernity/ Coloniality, and Nicaraguan American Social Processes.}

\section{RESUMEN}

Tanto la Historia Oral como método, como la corriente de pensamiento de la Alteridad, tienen relaciones temporales, puesto que se cosecharon próximos y después de la segunda guerra mundial. También se relaciona con la metódica militante, para no solo proponer un proceso anti hegemónico de construcción de la realidad e interpretación, sino la plataforma para que el protagonista en cualquier clase social o sector, narre, relate y determine el devenir de la historia otra, nueva. Las protagonistas de la historia de vida (oralidad) como caso de análisis, las tres mujeres son parte de un estudio que contribuye a validar otra historia, a narrar la historia del pueblo, fuera del poder, fuera de la tradición de conocimiento.

\section{ABSTRACT}

Both Oral History as method and the current of thought of Alterity have temporal relationships, since they were harvested near and after the Second World War. It is also related to the militant method, not only to propose an anti hegemonic process of construction of reality and interpretation, but also the platform for the protagonist in any social class or sector to narrate, relate and determine the future of another, new history. The protagonists of the history of life (orality) as a case of analysis, the three women are part of a study that contributes to validate another history, to narrate the history of the people, out of power, out of the tradition of knowledge.

\section{PALABRAS CLAVE}

\section{Historia Oral, modernidad/colonialidad, protagonista}

\section{KEY WORDS}

\section{Oral History, modernity/coloniality,} protagonist 


\section{Introducción}

$V^{\prime}$ incular la corriente del pensamiento de la Alteridad, también conocida como modernidad/ colonialidad (Escobar, A; 2007), al proceso de observación científico social de la Historia Oral, es darle mayores fundamentos metódicos a los procesos descolonizadores. Puesto que en la sociedad del conocimiento se deben formar sujetos con una conciencia libre y descolonizada para las sociedades/pueblos Nuestroamericanos. Donde los investigadores sociales y el protagonista directo de la historia "real o micro" -el sujeto que participa, construye, narra y testimonia la realidad-, desde sus relaciones intersubjetivas y trans-objetivas (el campesino que produce el alimento de los que gobiernan), con sus experiencias construye esa formación histórico social.

Reflexionar desde otras perspectivas epistémicas -horizontales, verdaderamente democráticas-, es el camino -método- con el cual las ciencias sociales, representantes de epistemologías emancipatorias, decoloniales, de la alteridad, sur-sur, teoría crítica y otras, han asumido el compromiso de construir, narrar y observar, desde los zapatos en el territorio del sujeto libre que es, participa y piensa, y con su verbo, tanto establecer la realidad, como deconstruir la "(ir) realidad" positiva, colonial, eurocentrada, tradicional que además de establecer un conocimiento de dominación, tales deben ser considerados por lo menos falacias, sino, el sistema ontológico y cognitivo de dominación no solo del ser, sino de la humanidad misma.

El estudio proporcionado por Romero A, J (2011) sobre tres mujeres en un contexto determinante tanto para ellas, ideas, valores, violencia colonialista, misoginia, necesidades materiales, al igual que para la mayoría de la población nicaragüense, son el camino que se debe retomar desde las ciencias sociales, para que la memoria de cada lucha sectorial o multisectorial, política, social, cultural y económica propongan en este siglo, desde el análisis de la memoria, de la historia de vida/oral, la historia justa de la mujer, de los pueblos.

\section{Historia tradicional "o" Historia nueva}

Aquí se realiza un análisis no historiográfico, pero sí una reflexión sobre la historia constitutiva de cada sociedad, de cada grupo social diferente, que organizaban sus memorias sociales, en momentos determinantes en la reestructuración y dominación de tanto civilizaciones, regiones o localidades inmediatas. Pues esos que reestructuraron, reinventaron y dominaron esos territorios en determinado momento, del tiempo de la humanidad pretérita, los vencedores, el poder hegemónico circunstancial, con violencia empezaron a narrar y organizar sus enfoques e intereses, a partir de un conocimiento e imaginarios que fungirían como plataformas para defender el poder de su coyuntura, pero negando y hasta borrando la historia, conocimiento, como realidades de las civilizaciones y grupos sociales o individuos vencidos, dominados, conquistados y colonizados.

La invención de la historia, en el imaginario del mundo blanco, occidental, capitalista sistematiza en los positivistas eurocéntricos y "colonias", parten de bases de corrientes de pensamiento desde las hegemonía capitalistas militares de los siglos XVIII y XIX, que eran y son hegemonías de conocimiento, de éticas, de valores y de sistemas, algunos representantes prominentes son Inmanuel Kant (1784) que hace un aporte sustantivo a la interpretación ética y lógica del imperio capitalista, pero también propone la narrativa de la historia nueva, cosmopolita con sesgo imperialista, o sea racista, en su obra Ideas para un historia universal en el sentido cosmopolita; 
en tanto Federico Hegel (1807) en su obra Fenomenología del espíritu, que crea categorías no solo conceptuales de análisis de reflexión o sea un conocimiento pasivo, sino que son aportes determinantes sobre la democracia, la historia del "espíritu absoluto", supone la teoría del neocapitalismo. Así mismo Augusto Comte (1844) con su obra Discurso del espíritu positivista construye de forma lapidaria la lógica de las bases de identidad, a partir del conocimiento determinado en las metrópolis imperialistas, aquel conocimiento propuesto fuera de estas era negado, o situado en la periferia, al margen.

En tal sentido, estas son la base sistémica de aquella historia hegemónica, eurocéntrica, capitalista, moderna, colonial. Cimientos que hasta en la actualidad, proyectan una fuerza en la educación, en la formación, en las relaciones sociales, que realizar un aporte ontológico del ser, solo puede realizarse desde bases filosóficas, alternativas, porque el eurocentrismo, puede llevarnos al mismo camino, a la negación y dominación del otro.

Las expresiones históricas se dan, desde las primeras tablas de arcilla con escritura cuneiforme, el papiro alejandrino o los manuscritos medievales, hasta la invención de la imprenta, el propósito óptimo de la historia ha sido la comunicación como medio para comprender al hombre. (Meyer \& Oliveira de Bonfil, 1971).

Los primeros historiadores como Herodoto (V a.n.e) -por ejemplo-, no se preocupó por narrar, relatar, describir, u observar las relaciones sociales ni ambientales, desde las circunstancias del oprimido, desde las relaciones sociales horizontales, sino, desde las condiciones hegemónicas, propias de sociedades coloniales o centros de poder. Éste narró aquellas cuestiones siempre relacionadas con el poder, la ética política griega, el ego conquiro de los reyes del Mar Egeo, cuya réplica y germen de la República esclavista de Platón, se reflejó en las sociedades inventadas del nuevo mundo, que también demandaba la póstuma historia que ahora nos define, con esos valores, pero con la historia alienada, aunque Hegel asumiera que el espíritu absoluto del Minerva era la mayor experiencia en la historia de la humanidad, tales criterios, solo contribuyeron a dominar y alienar a los pueblos originarios de Nuestra América.

El pensamiento social dominante en América Latina no es latinoamericano. Después de siglos de presión para pensar como "Ellos", la región más desigual del mundo grita indignada por justicia social, autonomía política, inclusión económica, cuidado ambiental, diálogo intercultural y desobediencia epistémica.

Eran autóctonos los constructores de caminos en Abya Yala hasta 1492, que incluían el color, olor, sabor, sonido y textura de los modos de ser, sentir, pensar, hacer y hablar de los pueblos originarios. Desde 1492, caminantes foráneos (españoles, portugueses, genoveses, conversos) destruyen antiguos caminos y construyen otros con los colores, olores, sabores, sonidos y texturas de sus modos de ser, sentir, pensar, hacer y hablar, y crean desigualdades, violencias e injusticias vinculadas a la idea de progreso/desarrollo constitutiva del capitalismo. (de Sousa Silva, 2008). 


\section{Sobre la Historia Oral y la Alteridad}

Nos dice Eugenia Meyer (1998), que es a partir de la década de los sesenta -yo diría que finalizando la de los cincuenta del siglo 20 , pues contamos en el baúl descolonizador con la gloriosa Revolución Cubana y sus barbudos anti imperialistas de 1959- cuando se producen las rupturas definitivas con formas de pensar y de actuar.

Infiere que "Metodológicamente se abrieron caminos diversos; de una visión funcionalista se decantó una perspectiva mucho más comprometida con la historia social, con la historia de los sin historia con la de esos protagonistas anónimos relegados por la crónica e historias oficialistas e institucionalizadas. Sin embargo..., no se trata ahora de una historia marginal. ..., es pues un esfuerzo por romper lanzas a favor de la otra historia, apoyada en instrumentos de trabajo más adecuados a la idiosincrasia latinoamericana, inserta en una corriente acorde con las especificidades y el quehacer nacional, que de cierta forma ajustaba los hilos sueltos del apretado tejido iniciado por los informantes de Sahagún, el cual vindica la oralidad de nuestro pueblo a lo largo de la historia de México. Se recuperaba la información de campesinos y obreros, de mujeres y hombres comunes, y no de las oligarquías o de las élites." (Meyer, 1998, p.130)

La Historia Oral representa una propuesta y oportunidad para, ya no el sabio, sino el investigador social, que además de la fuente oral (testimonio del protagonista) otras fuentes de datos e información escrita oficial, archivos o hemeroteca, se complementan para la evidencia necesaria y pertinente para demostrar hipótesis de hechos sociales. Se puede decir, que el objeto de la Historia Oral es avanzar en el conocimiento de la realidad pasada, participando desde un enfoque interdisciplinar de la historia que permite analizar el pasado desde puntos de vistas pluralistas. (Iturmendi, D. M., 2008, p.229).

\section{El propósito}

El principal objeto es que los sin voz, desde ese hecho, circunstancia o experiencia se construya la vida cotidiana urbana y rural. Ésta, acerca perspectivas de sectores más diversificados que los que trata la historia clásica (uni-versal, colonial y fija), actores que son tenidos en cuenta como marginales $\mathrm{u}$ opositores a los sectores que tradicionalmente detentan el poder.

De tal manera, que la "nueva" historia (historia otra) y desde sus investigaciones se dedican a averiguar la vida cotidiana, de los campesinos, la mujer, el obrero, los inmigrantes, minorías étnicas, el sexo, la moda, la cocina, etc. Es así, que se ha provocado la revaloración de los testimonios y documentos escritos, prestándole una mayor atención a los recuerdos, experiencias y puntos de vista de los testigos y actores del acontecer contemporáneo, personas que en sí mismas nunca, se han considerado protagonista del devenir histórico. (Iturmendi, D. M., 2008).

Con relación a los propósitos en la modernidad/colonialidad o también se reconoce con las Epistemología del Sur son el reclamo de nuevos procesos de producción, de valorización de conocimientos válidos, científicos y no científicos, y de nuevas relaciones entre diferentes tipos de conocimiento, a partir de las prácticas de las clases y grupos sociales que han sufrido, de manera sistemática, destrucción, opresión y discriminación causadas por el capitalismo, el colonialismo 
y todas las naturalizaciones de la desigualdad en las que se han desdoblado. Cuyas premisas se basan en una comprensión del mundo mucho más amplia que la comprensión Occidental del mundo; asume que la diversidad del mundo es infinita y que esta gran diversidad del mundo, que puede ser y debe ser activada, así como transformada teóricamente y prácticamente de muchas maneras plurales, no puede ser monopolizada por una teoría general. (de Sousa Santos, 2011)

Es en este sentido que también reflexionaba el guerrillero Tomás Borges Martínez (1991) fundador del Frente Sandinista de Liberación Nacional en Nicaragua-, que con Chomsky y Petras alzaban la pluma anti y postcolonialista, para motivar aquellos movimientos sociales y políticos hacia la ruptura del saber y ser del sistema mundo y la modernidad/colonialidad (....), al respecto sobre la esa historia "necesaria", dice que:

"Los europeos se esmeraron en construir un enorme escenario, en el cual los actores pueden ser observados desde muy lejos pero carecen de la posibilidad de reconocerse y de comunicarse entre si. El telón debe caer, para que esa pieza de teatro que llamamos historia sea vista por sus propios actores, con el fin de cambiar los diálogos y el previsible final, y sobre todo para que nuevos intérpretes de otras partes del mundo suban a escena." (Borges, 1991, pág. 54).

Es decir, se requería -y era imperativo por el anuncio del fin de la historia por Fukuyama, (1991)que las ciencias sociales y sus representantes, dieran otra perspectiva al conocimiento, para que desde la construcción de la realidad con los "nuevos interpretes" o protagonistas, los pueblos libres, y desde el territorio "locus" Nuestroamericano, del Abya Yala, cuyos cimientos de la génesis del capitalismo moderno e imperial, se deba realizar la propuesta histórica nueva de los sujetos, con la Oralidad, testimonios y otras fuentes, lo que implicaría un aporte, como condiciones donde el sujeto sea reconocido pero además se realice, con su condición de sujeto histórico y protagonista de tal realización social.

\section{El Sujeto, Protagonista (S )}

Porque el hombre -léase mujer también- debe asumir "la sorpresa de ser hombre/mujer", (Cioran, 1966), pues adquirir consciencia de ser hombre, cuando se está frente a sí mismo, y encontrar que se es algo diferente, esta contradicción dogmática del sujeto occidentalizado, lo convierte en un individuo alienado, incapaz siquiera de conocerse, de encontrarse, ni reconocerse parte de un colectivo, sino algo más del sistema mundo (Wallernstein, 1992), que dice que se es, o sea, el existir y el ser, pasa por los roles, funciones, "valores", objetivos que el sistema te establece, que te presupone individuo absoluto.

Y en la historia nueva, se continúa en construcción entonces, de las bases para una nueva definición de otro orden local, mundial y del sujeto a partir de su historia, que en sus expresiones, la historia oral libera de esa sorpresa al hombre de este otro mundo. Otro pues, es otro el conocimiento que define, a partir del mismo hombre, protagonista y actor social que testimonia su experiencia, criterios de su consciencia, que es la acción social, la transformación directa de la realidad. 


\section{La Historia Oral, el "nuevo sujeto histórico"}

En el siguiente caso, como evidencia del alcance de la Historia Oral (de Vida) y su relación tangible, "real y micro", con los procesos epistémicos de la alteridad o modernidad/colonialidad, se puede lograr establecer el gran vínculo con esa historia nueva, como aporte a la construcción de la realidad social, democrática, descolonizada, de género en este caso.

De modo que, desde y con la experiencia narrada de estas tres mujeres protagonistas, en pleno proceso emancipatorio socio-político, histórico, económico y cultural. La historia no solo real, sino violenta y anticolonial, anticolonialista, anti sistémica, por cuanto los hechos que determinan a estas protagonistas, son historia negada por la historia universal moderna, occidental, capitalista y democrática.

De tal manera que la evidencia que nos presenta la investigadora sobre "La vida de tres mujeres sandinistas: relatos de vida sobre la militancia del FSLN en los años sesenta en Nicaragua. Una mirada desde sus protagonistas", Jilma Romero Arrechavala (2011), citando a Martínez Burgos 1993, ese yo (mujer) cuenta la génesis de una persona que se convierte en narrador (ra) en el curso del relato: los acontecimientos que describe son las etapas de una experiencia por medio de la cual el sujeto desarrolla la dialéctica de la identidad y de la diferencia, la exclusión y la inclusión, la proximidad y la distancia. Que da cuenta de prácticas que lo asocian como individuo (único e irrepetible) y como miembro que se identifica con colectividades distintas.

Es así, es que el relato de las protagonistas: Yolanda Núñez, Ana Mercedes Baca Jeréz y María Magdalena Narváez Pineda, sobre las relaciones sociales intersubjetivas en aquella Nicaragua, que pujaba poco a poco desde cada sector, donde la Mujer comienza a jugar un papel relevante en la lucha social y política. De aquí que, la contribución desde estas actoras/protagonistas “...si- se tiene un sentido optimista de las cosas, se espera que con esfuerzo se pueda hacer algo mejor. Todas estaban ya involucradas en la militancia de izquierda y entonces ahí, la esperanza no era su prosperidad personal, la esperanza era tener la posibilidad de transformar el régimen político y cambiar la organización económica, para que de acuerdo al ideal, la gente tuviera un mejor nivel de vida, que el país pudiera superar la desnutrición, el analfabetismo y la pobreza en la que estaba sumida la mayoría de la población. Ninguna transformación social es posible si no se establece un mecanismo, una idea, una aproximación de lo que uno quiere, sustituir esa realidad que parece injusta. Entonces en ese sentido el mundo de las ideas interviene como el gran mediador para poder establecer una relación con el mundo." (Romero Arrechavala, 2011).

Se describe entonces, desde su relato, experiencia y ser, que para entrar a la historia se debe entrar contra las contradicciones y negaciones, que el sistema impone, la mujer, centrada en el retado de estas tres protagonistas, construye no solo la historia real, sino que desde su condición triple de dominación, es la fuente más importante de la construcción de esa historia otra, crítica y anticolonialista.

Estos relatos de las tres nicaragüenses rompen -como diría Meyer-, con realidades estáticas y raciales, y estableciendo una relación dialéctica, vindicativa con el pensamiento de la alteridad, así es que ciertas luces desde la transmodernidad Grosfoguel, R (2008), habla y deconstruye esa realidad hegemónica de las élites (historia del poder colonialista). 
Y es que rompen, transforman y construyen lejos de la ego-política del conocimiento el sujeto de enunciación queda borrado, escondido, camuflado en lo que Castro-Gómez, S (2005) ha llamado la filosofía del punto cero. Se trata entonces de una filosofía -historia absoluta eurocentrada y alienante- donde el sujeto epistémico no tiene sexualidad, género, etnicidad, raza, clase, espiritualidad, lengua, ni localización epistémica en ninguna relación de poder y produce la verdad desde un monólogo interior consigo mismo sin relación con nadie fuera de sí. Es decir, se trata de una filosofía sorda, sin rostro y sin fuerza de gravedad. El sujeto sin rostro flota por los cielos sin ser determinado por nada ni por nadie.

El conjunto de sujetos que narran y expresan, la cotidianidad, sus percepciones ideológicas como materiales, hacen que aquella historia positivista alienante, se diluya en las existentes plataformas del modelo de colonialismo vigente, tanto en los centros de estudio como sistemas corporativos de comunicación, que tienen por objeto mantener alienado a las personas, pueblos y regiones, de su verdadera realidad, además dispuesto a legitimar la característica violencia, con que le han robado la verdadera historia a los pueblos, sujetos y humanidad.

\section{Reflexiones Finales}

La realidad eurocentrada se sostiene en la historia universal, la cual niega el rol del sujeto protagonista, es decir, que cuando el sujeto establece su derecho a expresar su historia y testimonia su participación en esa historia, se rompen las tradiciones de dominio y comienzan las construcciones sociales democráticas.

El conjunto de sujetos que narran y expresan, la cotidianidad, sus percepciones ideológicas como materiales, hacen que aquella historia positivista alienante eurocéntrica, se diluya en las existentes plataformas del modelo de colonialismo vigente, tanto en los sistemas de educación como sistemas corporativos de comunicación, que tienen por objeto mantener alienados a las personas, pueblos y regiones, de su verdadera realidad; además dispuesto a legitimar la característica violencia, con que le han robado la verdadera historia a los pueblos, sujetos y humanidad. Por tanto, la Historia oral, deviene en una herramienta política de construcción política que convierte al "otro negado", al "dominado", en el protagonista, ante sistemas hegemónicos de conocimiento y de centro de poder.

Aunque con sus diferencias, tanto la historia oral propone una emancipación desde el relato del protagonista, las guerrilleras, que fueron comandantes, no solo ideológico políticas y militares, sino, que llevan el co-mandato de una ideología anticolonialista, el sandinismo antiimperialista, no solo para ellas es una forma de vivir, de existir, de pensar, de ser, sino que es un modo de hacer política para el propio pueblo que estas mujeres defendieron, de un modelo de dominación colonialista, hasta la síntesis de 1979. Siendo luego, éste un evento regional de nuestramerica y el caribe, como lo fue Cuba en 1959.

En tal sentido, también las corrientes de pensamiento de la Alteridad-modernidad/colonialidad/ epistemología sur-sur, desde un gran sistema de contradicciones, propone la reflexión antagónica, anti hegemónica, transmoderna, multi diversa, ya no "uni"-versal, a aquellos criterios o valores ontológicos del sistema mundo colonial, cual niega una historia, sujeto protagonista, etnias y culturas pluriversas, para imponer el "uni-versal" imperial, colonial y global. 


\section{Referencias bibliográficas}

- Borges, T. (1991). Perspectivas de la Lberación en América Latina. El Nuevo Orden Mundial o la conquista interminable , 49-61.

- Cioran, E. (1966). La caida en el tiempo. Paris: Papyre.

- Comte, A., \& Berges, C. (1965). Discurso sobre el espíritu positivo (No. 194.8 COM dis). Aguilar.

- de Sousa Santos, B. (2011). Formas-Otras (Saber, nombrar, narrar, hacer). CIDOB , 11-22.

- de Sousa Silva, J. (2008). Desobediencia epistémica desde el Abya Yala (América Latina). Campina Grande , 2-15.

- Dussel, E. (1994). 1492 El encubrimiento del Otro: Hacia el origen del" mito de la modernidad". Plural.

- Dussel, E., Mendieta, E., \& Bohórquez, C. (Eds.). (2009). El pensamiento filosófico latinoamericano, del Caribe y" latino"(1300-2000): historia, corrientes, temas y filósofos. Siglo XXI.

- Escobar, A. (2007). El giro decolonial: reflexiones para una diversidad epistémica más allá del capitalismo global. Siglo del Hombre.

- Grosfoguel, R. (2008). Hacia un Pluri-versalismo transmoderno Decolonial. Tabula Rasa , 199-215.

- Hegel, J. G. F. (1985). Fenomenología del espíritu, trad. de Wenceslao Roces, 6a. reimpr. México, FCE.

- Iturmendi, D. M. (2008). La historia oral como método de investigación histórica. Gerónimo de Uztariz, (23), 227-233.

- Kant, I. (2006). Idea para una historia universal en clave cosmopolita (Vol. 36). UNAM.

- Meyer, E. (1998). Decontrucción de la Memoría, Construcción de la Historia. Historia, Antropología y Fuentes Orales , 127-135.

- Meyer, E., \& de Bonfil, A. O. (1971). La historia oral. Origen, metodología, desarrollo y perspectivas. Historia mexicana, 21(2), 372-387.

- Restrepo, E., \& Rojas, A. (2010). Inflexión decolonial: fuentes, conceptos y cuestionamientos. Popayán: Universidad del Cauca.

- Romero Arrechavala, J. (2011). La vida de tres mujeres sandinistas: relatos de vida sobre la militancia del FSLN en los años sesenta en Nicaragua. Una mirada desde sus protagonistas. Caminos de Historia y Memoria en América Latina , 261-275. 


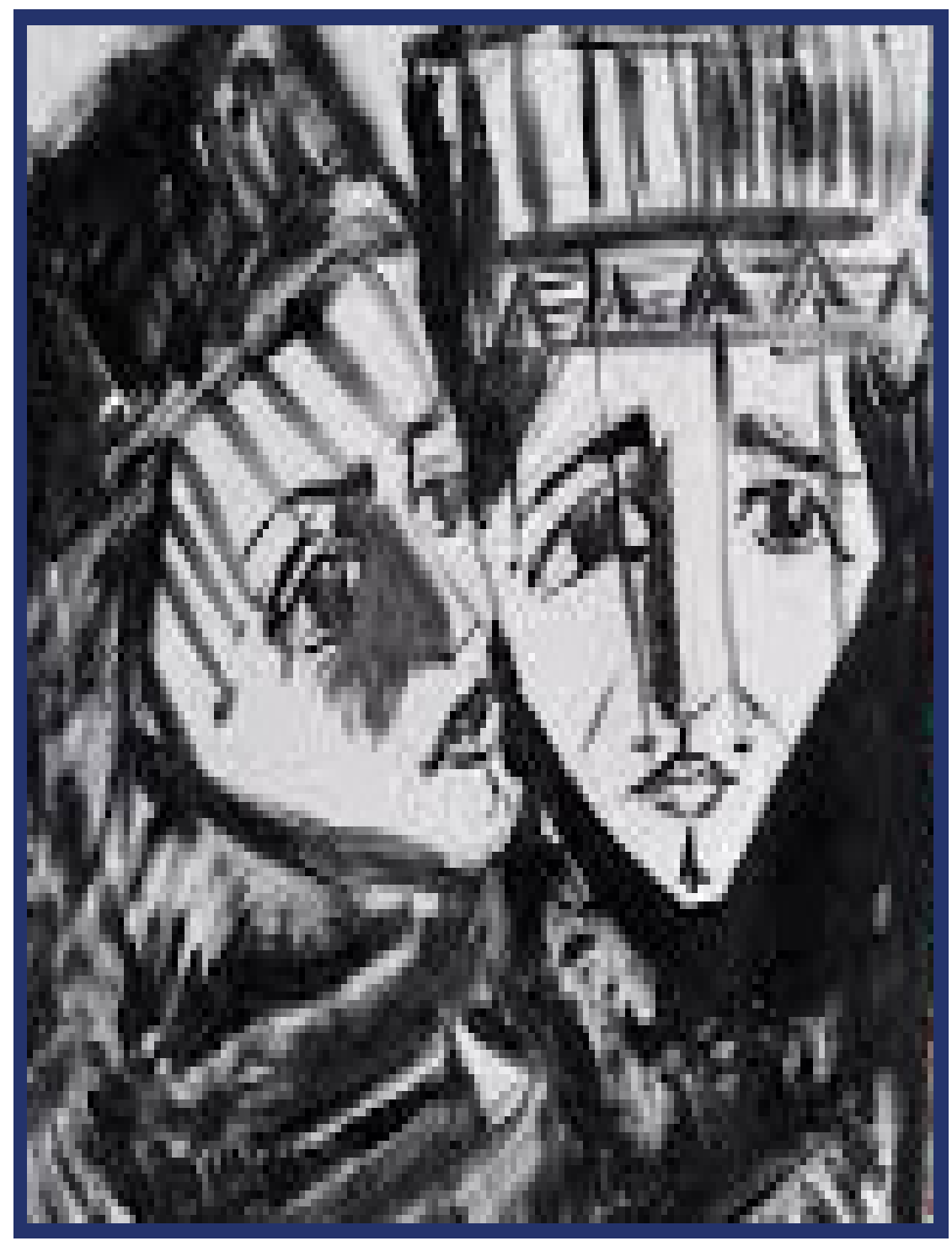

http://www.kedistan.net/

MSc. Leonardo Danilo González E.

Abogado, Master en métodos de investigación científica. Docente de la Facultad de Ciencias e Ingeniería. UNAN-Managua.

https://orcid.0000-0003-3158-737X

leochorotegaunan@gmail.com 